\title{
An Mediated Effect Analysis of Purchasing Intention Under Social Media_from the Chinese Motion Industry
}

\author{
Yu Liu, Li Zhang, Shu-Yan Cao \\ School of Information Technology \& Management, University of International Business and Economics, Beijing, China \\ Email address: \\ tasummer@sina.com (Li Zhang),yuliu201511@163.com (Yu Liu)
}

\section{To cite this article:}

Yu Liu, Li Zhang, Shu-Yan Cao. An Mediated Effect Analysis of Purchasing Intention Under Social Media—from the Chinese Motion Industry. International Journal of Economics, Finance and Management Sciences. Vol. 6, No. 3, 2018, pp. 124-132. doi: $10.11648 /$ j.ijefm.20180603.18

Received: April 27, 2018; Accepted: June 6, 2018; Published: June 20, 2018

\begin{abstract}
In recent years, with the development of online social media and motion industry, online social media has more and more influence on movie marketing. How to improve consumers' purchase intention and purchase behavior through social media has been becoming a research hotspot among the scholars. Based on the Chinese market movie data from the product information, marketing interactive information, internet word-of-mouth, respectively, to verify the intermediary role of purchase intention, and then put forward the corresponding film marketing strategies according to the empirical results. The results showed that there was significantly positively correlated between the online word-of-mouth, marketing interactive information and purchase intention, among which the number of comments and topics had the greatest influence on purchase intention. In addition, the purchase intention could significantly affect the purchase behavior, verifying the purchase intention played a partial intermediary role in the overall consumption decision.
\end{abstract}

Keywords: Purchase Intention, Mediating Role, Film Marketing, Social Media, Internet Word-of-Mouth

\section{Introduction}

Socialized e-commerce has been developing rapidly in recent years, and social media emerge as platforms for people to create, share, discuss and generate contents, such as Dou-Ban, Weibo, WeChat, etc. In this way, people can accurately obtain the contents they are interested in through search engines. Moreover, It is also used as a channel for advertising and marketing information to foster consumers' purchasing intention, which brings new marketing patterns for product marketing. In the social media environment, how to cultivate consumers' willingness to purchase and improve marketing effectiveness has become a research hotspot for scholars, and some valuable researches results have been obtained [1-14]. However, the current purchase intention researches mainly use the establishment of a scale to obtain primary data. And yet, the development of social media and programming tools provides a terrace for the collection of second-hand data. These second-hand data also can accurately reflect consumers' psychology behaviors. Therefore, this paper uses the collected Chinese film data to verify the mediating effect of purchase intention under the social media environment, so as to formulate effective marketing strategies to improve marketing effectiveness.

\section{Literature Review and Hypotheses}

\subsection{Model and Hypotheses}

The concept of desire originated in psychology, which was used to describe the subjective concept of individuals engaged in a particular behavior [9], and was a sense of human behavior. In marketing, Mullet concluded that the consumer's personal attitudes toward the product or brand combined with external factors, which constituted the consumer's willingness to buy [8]. According to Ajzen et al., Customers took actions based on their willingness to a particular object. Only when the customer has the intention to purchase can they make the purchase decision. Hence, customers' purchase behaviors could be predicted by acknowledging the purchase intention of the customers [9]. At present, scholars pay more and more attention to product cognition, purchase intention, purchase behavior and decision-making factors, and have made many academic 
achievements [1-14].

Previous studies had found that "marketing information" of relevant products provided by enterprises could influence consumers' attitudes, feelings and perceptions about the product, then affected the consumers' purchase willingness and behaviors [3]. Furthermore, the enterprises and individuals enabled to establish good corporate images or promote product to cultivate consumers' purchase intention by publishing various kinds of online marketing activities and interacting with fans periodically or irregularly on the social media such as Weibo [10]. Bei Zhang also believed that consumers were affected by external marketing stimulus such as marketing mix (including products, promotions) and marketing environment, then motivate their willingness to purchase which in turn affected consumer behavior. And the purchase willingness played an intermediary role between marketing stimulus and buying behavior [11].

In addition, Jidong $\mathrm{Bi}$ used technology acceptance model to establish the relationship between the Internet word-of-mouth and the purchase willingness from the perspective of customer perception. And the empirical results showed that the variables under individual differences and customer perception indeed had a positive or negative impact on purchase intention [12]. Through the introduction of social capital theory, Wenming Zuo constructed the relationship model of Internet word-of-mouth and the purchase intention from the perspective of social capital. The results showed that the quality and quantity of Internet word-of-mouth significantly affected the purchase willingness, and the quantity had a greater impact on purchase intention [13]. X Du regarded online reviews as an object of study, and established the online reviews model of the impact on purchase intention. The conclusion showed that the online reviews value factors including the number of reviews, the quality of reviews and the reviews' valence, positively influence consumers' purchase willingness [14].

According to above literature review, this article set up a theoretical model of the marketing information, online word-of-mouth, purchase intention and purchase behavior, which was shown in figure 1. The marketing information includes product information, marketing interactive information. And the purchase intention is regarded as mediating variables between the marketing information, Internet word-of-mouth (IWOM) and purchase behaviors. That is, the marketing information and internet word-of-mouth influence the purchase behavior through affecting purchase intention.

Film as a digital product, social media marketing also brings opportunities for its development. Currently, the researches on film marketing mainly focus on two aspects: the influencial factors of movie box office incomes and the prediction of box office revenues. Scholars analyzed the related characteristics of movie product (such as director, starring, movie genre, release date, etc.), also studied the network word-of-mouth, network search volume, trailers and other aspects under the social media perspective. Those all impacted the box office. There have been a lot of researches [15-30], and the conclusions are in Table 1 below.

Table 1. Scholars' researches summery.

\begin{tabular}{|c|c|c|}
\hline Author and time & Variables & Conclusions \\
\hline Ravid \& Basuroy(2004) [15] & Genre & R-rated violent genre films can affect ticket sales, and often have better incomes \\
\hline Sochay(1994) [16] & Release date & Summer vacation is the best time to launch the movies \\
\hline Radas \& Shugan(1998) [17] & Release date & $\begin{array}{l}\text { the movie launched in hot schedule, whose life was not long, but the box office revenues were } \\
\text { very high }\end{array}$ \\
\hline Prag \& Casavant (1994) [18] & Star power & Stars' power can significantly affect the box office revenues \\
\hline Chang t al.(2005) [19] & Star power & Stars only affect the first week's box office revenues \\
\hline $\mathrm{X} \mathrm{Wu}(2008)[20]$ & Director power & Directors' power are usually greater than the star \\
\hline $\mathrm{X} \mathrm{Hu}(2013)[21]$ & Country of production & Country of movie production have a significant impact on the box office \\
\hline K Guo(2016) [22] & Number of reviews & $\begin{array}{l}\text { The number of online reviews significantly and positively impact box office incomes, and } \\
\text { online score also significantly influence the number of online reviews }\end{array}$ \\
\hline Y Hao(2009) [23] & $\begin{array}{l}\text { Sentimental } \\
\text { orientation reviews }\end{array}$ & $\begin{array}{l}\text { The impact of online movie review sentimental orientation on movie incomes is significant, } \\
\text { even exceeding that of reviews volume. }\end{array}$ \\
\hline Z Liu(2016) [24] & Rating & $\begin{array}{l}\text { Online rating has a significant impact on the movie box office, but does not rule out the "navy" } \\
\text { on the score }\end{array}$ \\
\hline Y Zhong(2017) [25] & Length of run & It is used as a movie-making information in a machine learning model of copyright valuation \\
\hline $\operatorname{Shugan}(2009)[26]$ & Willingness to watch & $\begin{array}{l}\text { they collected data on the wishes of the film through playing trailers, and found that the index } \\
\text { can greatly improve the ability to explain the box office }\end{array}$ \\
\hline Lian Wang(2014) [27] & Web search volume & $\begin{array}{l}\text { Use the web search volume as a predictor of box office prediction and the purchase intention for } \\
\text { consumers }\end{array}$ \\
\hline C Sun(2017) [28] & Trailers & $\begin{array}{l}\text { The time to market, number and length of the trailers have a significant effect on the number of } \\
\text { the trailer's attention, and the number of trailer's attention and emotion of trailer's comments } \\
\text { have a significant effect on the box office incomes }\end{array}$ \\
\hline
\end{tabular}


Table 2. Affected factors of purchase behavior.

\begin{tabular}{ll}
\hline First & second \\
\hline & Length of run of the film \\
Product information & Movieperson power \\
& Country of production \\
& Release date \\
Marketing interactive information & Trailers playing volume \\
& Number of topics \\
& Number of reports \\
Online word-of-mouth & Number of reviews \\
& Rating \\
Purchase intention & Number of rating people \\
\hline
\end{tabular}

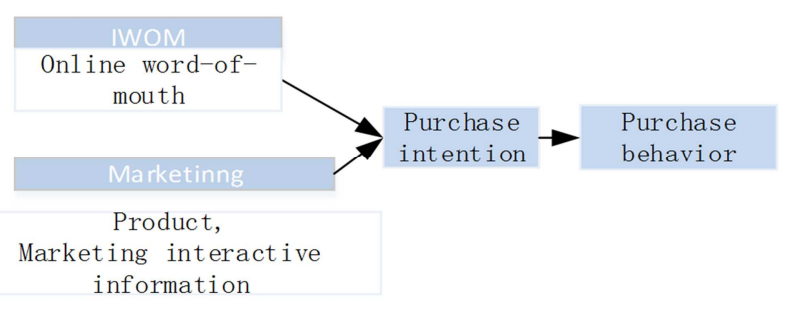

Figure 1. IWOM, marketing information, purchase intention and purchase behavior model.

Due to the Chinese films are different from the United States and other countries, where they have a classification system (the films were divided into R, G-Rating, etc.). Films are divided by genres in our country. But a movie has multiple genres, if we divided it by a particular genre, which is subjective. Also, Ravid (1999) argued that subdividing a movie into groups by genre was subjective, in fact, quite a few movies were hard to classify [29]. Therefore, this article no longer considers the movie genres. According to the existed researches' conclusions, we combine with the model in Figure 1. The influencial factors of purchasing behavior are shown in table 2, which are applied to verify the mediating effect of purchasing intention from three aspects - product information, marketing interactive information and online word-of-mouth, by using Chinese motion industry market data.

1) Product information and purchase intention

Consumers used to evaluate product information based on their existed knowledge and experience to determine whether they have purchase intention. For example, there are famous directors and actors who consumers are acquained with in the movie, they may have more purchase willingness. Therefore, we lead to the following hypotheses:

H1a: Films length can significantly affect purchase intention.

HIb: Country of production are related to the purchase intention.

H1c: Movieperson power can positively and significantly affect purchase intention.

H1d: Releasing date could significantly impact purchase intention.

2) Marketing interactive information and purchase intention

Ridings pioneeringly studied the possible relationships between the nature of mutual information and cognitive trust in the virtual cyberworld. The result shown that the quality and quantity of information changed in the same direction as the consumer's trust [30], and then impacted on purchase intention. The more film trailers playing volume, topics and reports are, the higher the consumers' responses of the film are, which indicates the popularity of the film. By browsing this information, consumers are addicted into the topic circles. In this way, they are more able to stimulate consumer curiosity and purchase intention. So it is assumed as follows:

H2a: The number of topics can moderate purchase intention positively and significantly.

$H 2 b$ : The trailer playing volume of each film and purchase intention are positive and significant relationship.

H2c: The number of media reports could significantly influence the purchase intention, and they are positive relationship.

3) Internet word-of-mouth(IWOM) and purchase intention

When consumers receive word-of-mouth information, it will affect not only their purchasing behavior, but also their brand awareness and attitude [31]. Chatterjee found when consumers made purchase decision, their unease would decline after reading a amount of others' reviews. Because consumers thought other consumers would comsume the same product [32]. W Zuo argued that Internet word-of-mouth significantly affected the purchase intention, which included the number of Internet word-of-mouth and valence of online word-of-mouth. However, the number's impact was relatively greater [13]. The more sources of word-of-mouth information are, the greater the impact on consumers' willingness to buy and decisions are. Therefore we propose the following assumptions:

H3a: The rating has a positive and significant relationship with purchase intention.

H3b: The number of online reviews can have a positive and significant effect on purchase intention.

4) Purchase intention and purchase behavior

The stronger the purchase intention is, the more likely it is to buy. Thus:

H4: Purchase intention significantly affect purchasing behavior, and they are positively correlated.

\subsection{Variables Definition}

There are some quantitative variables and qualitative 
variables. In order to clearly reflect the impact of these variables on the box office revenues and improve the accuracy of the model, virtual variables are introduced to quantify the qualitative variables. The quantitative variables of this article are releasing date, country of prodution. Through the above theoretical assumptions, table 3 presents the definition of various influencial factors.

Table 3. Variables definition.

\begin{tabular}{llll}
\hline Variables type & Variables name & Symbol & Definition \\
\hline Dependent variable & Purchase behavior & $b f$ & Movie's box office revenues \\
Mediating variable & Purchase intention & $w n$ & The number of people who want to see the movie \\
& The length of run & $t$ & The length of run of each movie in the theater \\
& Movieperson power & $a w$ & The total number of awards or nominations of director and top 2 actors in film Festival \\
& Country of production & $c t$ & 1=China, 2=America, 3=French, 4= Britain, 5=Japan, 0=Other \\
& Release date & $d q$ & 1=new year, 2=may day, 3=national day, 4=summer holiday, 0=Other \\
Rating & $s$ & Average score of each movie \\
Independent & Online reviews & $c n$ & The total number of each movie's online reviews \\
variables & Number of rating people & $p e$ & The total number of people who rated the film \\
& Number of trailers playing & $y n$ & The total trailers playing volume of each film in Tencent, SOHU, IQY videos and so on \\
& Number of topics & $t n$ & The total number of each movie's relevant topics \\
& Number of reports & $m n$ & The total number of movie reports in the various major media \\
\hline
\end{tabular}

Note: Domestic awards includes five categories: Golden Rooster, Hundred Flowers, Ornamental Column, Hong Kong Film and Golden Horse award. International awards also divides five categories -- Academy, Golden Ball, Golden Palm, Golden Bear and Golden lion award.

\section{Empirical Research}

Due to movies are real-time products, and consumers' behavior data on social media are only used in recent years. Therefore, this paper chooses the top 130 movies of the top box office incomes in 2014-2017 as the sample data, which includes 507 movies and more than 6000 pieces of data after deleting the missing and abnormal data. Films relevant information and box office incomes are from the Douban.com, the number of topics, the amount of trailer and media reports are from Entgroup.com. Douban.com is the largest and most authoritative movie community, and provides consumers with real ratings and wonderfully high-quality online film comments. Moreover, Entgroup.com is the first research institute of entertainment industry in China that provides timely and comprehensive information and services to the entertainment industry related practitioners.

\subsection{Statistical Data Description}

This article uses spss20 software to deal with the data, first we utilize the correlation analysis to initially verify the hypothesis, and finally make use of linear regression to test the purchase intention's intermediary effect.

1) Descriptive statistics

Due to the large difference among the box office incomes that some are as many as hundreds of millions, but some are as little as 1 million. This paper reduces its heteroscedasticity by logarithm. Similarly, $c n, y n, \mathrm{mn}$ and wn also decrease heteroscedasticity by logarithm. Then, each variable is normalized, if the Z-values $>2$, which are treated as outliers, then remove them. The final result is shown in Table 4 where shows the approximate distribution of each variable.

Table 4. Descriptive statistics.

\begin{tabular}{llllll}
\hline Variables & Sample & Min & Max & Mean & Sd \\
\hline$b f$ & 436 & 14.960 & 21.200 & 18.176 & 1.414 \\
$s$ & 436 & 2.500 & 9.200 & 5.817 & 1.489 \\
$t$ & 436 & 79.000 & 169.000 & 106.055 & 15.010 \\
$c t$ & 436 & 0.000 & 5.000 & 1.475 & 1.000 \\
$d q$ & 436 & 0.000 & 4.000 & 1.720 & 1.519 \\
$a w$ & 436 & 0.000 & 29.000 & 8.619 & 7.571 \\
$w n$ & 436 & 5.560 & 11.090 & 8.447 & 1.202 \\
$t n$ & 436 & 0.000 & 5.790 & 2.452 & 1.449 \\
$y n$ & 436 & 0.000 & 11.300 & 5.367 & 3.009 \\
$m n$ & 436 & 2.560 & 6.490 & 4.517 & 0.812 \\
$C n$ & 436 & 6.045 & 12.149 & 9.222 & 1.509 \\
$P e$ & 436 & 6.632 & 13.140 & 9.995 & 1.590 \\
\hline
\end{tabular}

2) Correlation analysis

Pearson correlation analysis is used to test whether the hypotheses are valid. Thus, the correlation analysis was conducted between product information, marketing interaction information, online word-of-mouth and purchase intention, also between purchase intention and purchase behavior.

As can be seen in table 5, all independent variables are significantly related to purchase intention, and purchase intention is also significantly related to purchase behavior, which initially verifies our hypothesis. In table 6 , the correlation coefficient between cn and pe is $0.995>0.8$, which illustrates that there is a high correlation between them. Because this article focuses on the number of comments, we will delete $p e$.

Table 5. Correlation analysis between purchase intention and other variables.

\begin{tabular}{|c|c|c|c|c|c|c|c|c|c|c|c|}
\hline & \multicolumn{4}{|c|}{ Product information } & \multicolumn{3}{|c|}{ Marketing interactive information } & \multicolumn{3}{|l|}{ IWOM } & \multirow{2}{*}{$\begin{array}{l}\text { Purchase behavior } \\
\text { bf }\end{array}$} \\
\hline & $c t$ & $T$ & $A w$ & $d q$ & $m n$ & tn & yn & $s$ & $c n$ & pe & \\
\hline$w n$ & $.333 * *$ & $.517 * *$ & $.362 * *$ & $-.100 *$ & $.464 * *$ & $.740 * *$ & $.229 * *$ & $.707 * *$ & $.861 * *$ & $.860 * *$ & $.615^{* *}$ \\
\hline
\end{tabular}

'**', and '*' represent $1 \%$ and $5 \%$ significance levels using a two-tailed test, respectively. 
Table 6. Correlation analysis of independent variables.

\begin{tabular}{|c|c|c|c|c|c|c|c|c|c|c|}
\hline & $C t$ & $t$ & $s$ & $A w$ & $d q$ & $c n$ & $m n$ & $t n$ & pe & $p n$ \\
\hline$c t$ & 1 & & & & & & & & & \\
\hline$t$ & $.153^{* *}$ & 1 & & & & & & & & \\
\hline$s$ & $.403 * *$ & $.373 * *$ & 1 & & & & & & & \\
\hline$a w$ & 0.06 & $.430 * *$ & $.206^{* *}$ & 1 & & & & & & \\
\hline$d q$ & $-.118 *$ & -0.056 & -0.082 & $-.141 * *$ & 1 & & & & & \\
\hline$m n$ & 0.014 & $.452 * *$ & $.213^{* *}$ & $.283^{* *}$ & $.147 * *$ & $.607 * *$ & 1 & & & \\
\hline$t n$ & $.175^{* *}$ & $.457 * *$ & $.449 * *$ & $.276^{* *}$ & 0.021 & $.688 * *$ & $.477 * *$ & 1 & & \\
\hline pe & $.237 * *$ & $.579 * *$ & $.608 * *$ & $.455^{* *}$ & $-.102 *$ & $.995 * *$ & $.582 * *$ & $.656^{* *}$ & 1 & \\
\hline$p n$ & $-.128 * *$ & $.174 * *$ & 0.076 & $.184^{* *}$ & $.183^{* *}$ & $.341 * *$ & $.382 * *$ & 0.042 & $.346^{* *}$ & 1 \\
\hline
\end{tabular}

'**', and '*' represent $1 \%$ and $5 \%$ significance levels using a two-tailed test, respectively.

\subsection{Result Analysis}

Although the pearson correlation initially tests the hypothesis, it still can not fully explain the relationship between product information, marketing interaction information, internet word-of-mouth and purchase intention. Therefore, we use linear regression analysis to explore their relationship detailedly.

In order to verify the intermediary effect of purchase intention and the relationship between purchase intention and all independent variables, the regression analysises between product information, marketing interaction information and online word-of-mouth are performed respectively.

As were shown in Tables 7, 8 and 9, the three models in each table represent the following three steps respectively: the first, the regression analysis between the independent variable and the dependent variable purchase behavior; the second, the regression analysis of the independent variables and the intermediate variable purchase intention; the third, regression analysis of intermediary variable and dependent variable purchases behaviour.

The flow chart is used to judge whether purchase intention plays a mediating role, as is shown in Figure 2. In addition, the standardized coefficients of the second model in each table are used to compare the effect of different independent variables on the dependent variable. The larger the absolute value of the standardized coefficient is, the greater its effect on the dependent variable is.

Table 5. Regression analyses of product information, purchase intention and purchase behavior.

\begin{tabular}{|c|c|c|c|c|c|c|c|c|}
\hline & & \multicolumn{2}{|l|}{ Model 1} & \multicolumn{3}{|l|}{ Model 2} & \multicolumn{2}{|l|}{ Model 3} \\
\hline & & $\begin{array}{l}\begin{array}{l}\text { Unstandardized } \\
\text { coefficient }\end{array} \\
\end{array}$ & $p$-Value & $\begin{array}{l}\begin{array}{l}\text { Unstandardized } \\
\text { coefficient }\end{array} \\
\end{array}$ & $\begin{array}{l}\text { standardized } \\
\text { coefficient }\end{array}$ & p-Value & $\begin{array}{l}\text { Unstandardized } \\
\text { coefficient }\end{array}$ & $p$-Value \\
\hline \multirow{4}{*}{$\begin{array}{l}\text { Independent } \\
\text { variables }\end{array}$} & (constant) & 13.437 & 0.000 & 4.367 & & 0.000 & 10.740 & 0.000 \\
\hline & $c t$ & 0.037 & 0.535 & 0.311 & .259 & 0.000 & -0.155 & 0.005 \\
\hline & $t$ & 0.042 & 0.000 & 0.032 & .403 & 0.000 & 0.022 & 0.000 \\
\hline & $a w$ & 0.024 & 0.006 & 0.027 & .170 & 0.000 & 0.007 & 0.358 \\
\hline \multirow{5}{*}{$\begin{array}{l}\text { Mediating } \\
\text { variable }\end{array}$} & $d q$ & 0.046 & 0.243 & -0.018 & -.023 & 0.566 & 0.057 & 0.097 \\
\hline & $w n$ & ------ & ------ & ------ & ------ & ------ & 0.618 & 0.000 \\
\hline & VIF max-value & 1.253 & & 1.253 & & & 1.558 & \\
\hline & F-value & 38.068 & & 60.085 & & & 67.052 & \\
\hline & $F$-prob & $.000 \mathrm{~b}$ & & $.000 \mathrm{~b}$ & & & $.000 \mathrm{~b}$ & \\
\hline
\end{tabular}

Table 6. Regression analyses of marketing interactive information, purchase intention and purchase behavior.

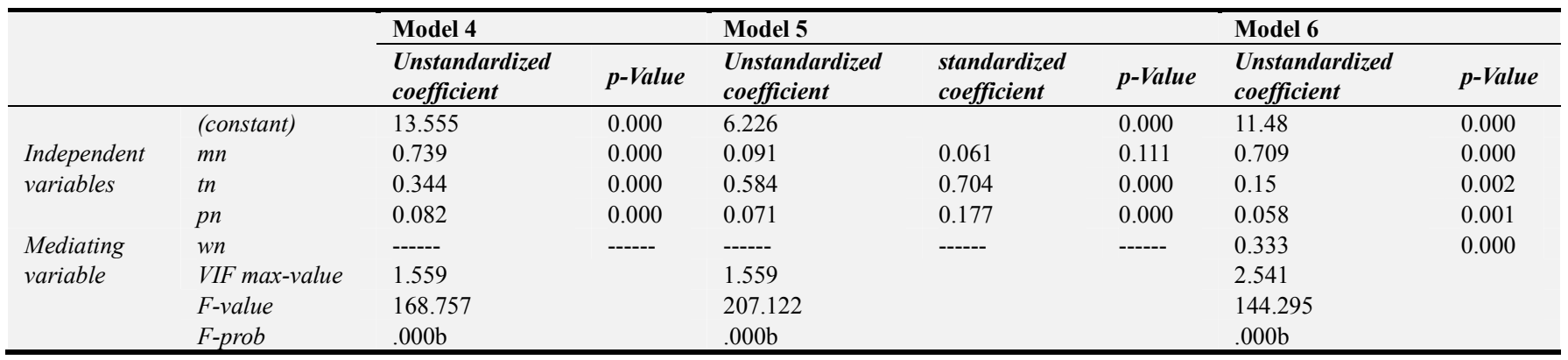


Table 7. Regression analyses of online word-of-mouth, purchase intention and purchase behavior.

\begin{tabular}{|c|c|c|c|c|c|c|c|c|}
\hline & & \multicolumn{2}{|l|}{ Model 7} & \multicolumn{3}{|l|}{ Model 8} & \multicolumn{2}{|l|}{ Model 9} \\
\hline & & $\begin{array}{l}\text { Unstandardized } \\
\text { coefficient }\end{array}$ & p-Value & $\begin{array}{l}\text { Unstandardized } \\
\text { coefficient }\end{array}$ & $\begin{array}{l}\text { standardized } \\
\text { coefficient }\end{array}$ & p-Value & $\begin{array}{l}\text { Unstandardized } \\
\text { coefficient }\end{array}$ & p-Value \\
\hline \multirow{3}{*}{$\begin{array}{l}\text { Independent } \\
\text { variables }\end{array}$} & (constant) & 11.539 & 0.000 & 1.985 & & 0.000 & 11.907 & 0.000 \\
\hline & $s$ & -0.1 & 0.005 & 0.253 & .314 & 0.000 & -0.053 & 0.192 \\
\hline & $c n$ & 0.783 & 0.000 & 0.541 & .679 & 0.000 & 0.883 & 0.000 \\
\hline \multirow{4}{*}{$\begin{array}{l}\text { Mediating } \\
\text { variable }\end{array}$} & $w n$ & ------ & ------ & ------ & ------ & ------ & -0.185 & 0.021 \\
\hline & $\begin{array}{l}\text { VIF } \\
\text { max-value }\end{array}$ & 1.506 & & 1.506 & & & 5.174 & \\
\hline & F-value & 334.814 & & 903.655 & & & 227.235 & \\
\hline & F-prob & $.000 \mathrm{~b}$ & & $.000 \mathrm{~b}$ & & & $.000 \mathrm{~b}$ & \\
\hline
\end{tabular}

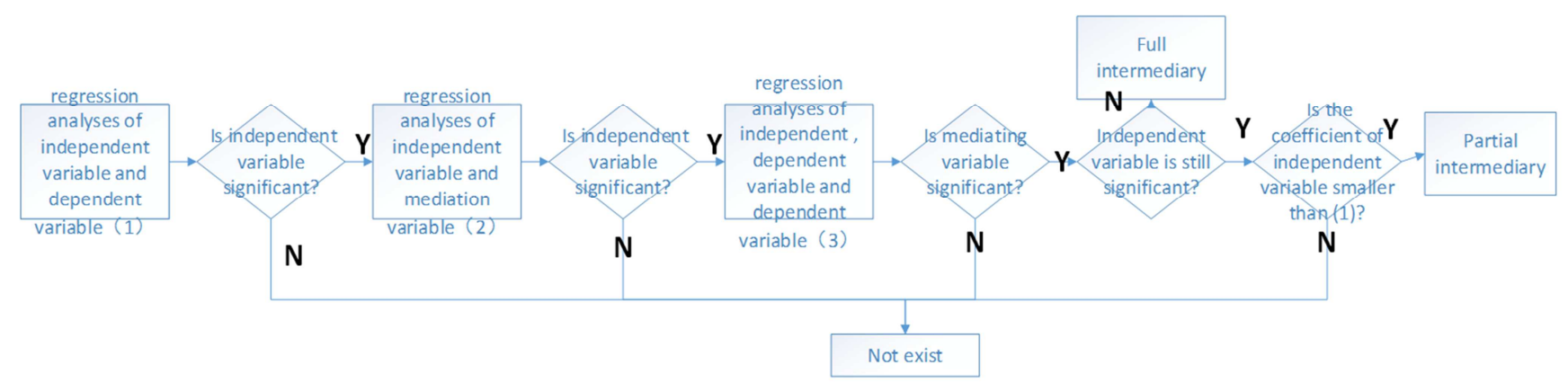

Figure 2. The flow chart to determine mediation effect.

1) Product information and purchase intention

From model 2 in table 7 , we can see that the coefficients of $c t$, aw and $t$ are all greater than 0 , and their $p$-value $<0.05$, so the result shows that $c t, a w$ and $t$ are significantly and positively related to purchase intention $w n$, respectively, supporting Hla, H1b, Hlc. It suggests that the bigger movie-person power is the more popular the actors and directors are. Consumers will have more willingness to buy tickets. Moreover the standardized coefficient of $t$ is the largest in model 2, indicating that the length of run of each film has the greatest impact on purchase intention. However, purchase intention has no significant impact on the releasing date. Therefore, H1d does not hold.

2) Marketing interactive information and purchase intention

Similarly, the model 5 of table 8 presents the effect of $m n$, tn and $p n$ on purchase intention, respectively. The result shows that the coefficients of the interaction terms between purchase intention and the two marketing interactive variables $t n, p n$ are significantly positive $(p<0.05)$. The hypothesis $H 2 a, H 2 b$ hold. The results imply that the more number of topics and trailers playing volume are, the more purchase willingness is. However, there is no significant correlation between the number of media and purchase intention, so $\mathrm{H} 2 \mathrm{c}$ does not hold. The reason may be that the more number of main media reports are the more possibility of hyping consumers feel. This maybe decline purchase willingness. what's more, $t n$ has the greater influence on the purchase intention than pn because of its maximum standardized coefficient in model 5.

3) Internet word-of-mouth and purchase willingness

Model 8 of table 9 tests wether Internet word-of-mouth can significantly impacts purchase willingness. And the result shows that the coefficients of the interactions terms between cn, $\mathrm{s}$ and purchase intention are significantly positive $(\mathrm{P}<$ 0.05) supporting $H 3 a, H 3 b$. This implies that the more reviews are, or the higher the rating is the stronger purchase intention is Moreover the number of reviews cn have the greatest impact on purchase intention.

4) Purchase intention's intermediary effect

Next we will discuss whether purchase intention plays the intermediary role in table 7,8 and 9 , respectively.

In table 7 , the result of model 1 shows that $t$ and $a w$ are significantly and positively related to dependent variable bf. At the same time, The coefficients of the interaction terms between them and mediation variable wn are positive and significant $(\mathrm{P}<0.05)$ in model 2 , implying that they can significantly and positively impact $w n$. Furthermore, I n model 3 , the mediating variable $w n$ is significant $(\mathrm{p}<0.05)$. aw is not significant, suggesting that purchase intention plays a fully intermediary role. That is, aw perfectly influence purchase behavior through purchase intention. However, $t$ is still significant, and its unstandardized coefficient is smaller than Model 1, so purchase intention plays a partial intermediary role between $t$ and $b f$, showing that $t$ impacts bf to some extent through purchase intention.

In table $8, t n$ and $p n$ significantly and positively affect not only $b f$, but also $w n$. And $w n$ is significantly and positively related to bf. Moreover, the unstandardized coefficients of tn and pn both are smaller than model 4. Thus, purchase intention exists partial intermediary effect between number of topics, number of trailer playing and purchase behavior. By the same token, from table $9, \mathrm{~s}$ is fully based on the purchase intention to affect purchase behavior. That is, purchase intention plays a clearly mediating role.

Above all, we summarize that purchase willingness plays partial intermediary role between purchase behavior and product information, marketing interactive information, 
online word-of-mouth, respectively. All independent variables are to some extent affect the purchase intention, which then impacts the purchase behavior.

In addition, from the third model in table 7,8 and 9, respectively, there are significant relationships between purchase intention and purchase behavior. Among them, purchase intention is positively related to purchase intention in product information and marketing interactive information.
But in the aspect of word-of-mouth, purchase intention and purchase behavior are negatively correlated. There may be too much Internet word-of-mouth information to make comsumer overload, the large information cause the illusion of good film quality that easily lead to impulsive purchase intention. Instead, consumers' purchase willingness maybe decline after calming down, which results in no purchase behavior. Table 10 shows conclusions.

Table 8. Conclusions summary.

\begin{tabular}{|c|c|c|c|c|}
\hline & variables & hypothesis & hypothesis holds? & Intermediary role? \\
\hline \multirow{4}{*}{ Product information } & Length of run & Hla & hold & Partial intermediary \\
\hline & Country of production & $H 1 b$ & hold & no \\
\hline & Movieperson power & $H 1 c$ & hold & Full intermediary \\
\hline & Release date & HId & Not hold & no \\
\hline \multirow{3}{*}{ Marketing interactive information } & Number of topics & $H 2 a$ & hold & Partial intermediary \\
\hline & Number of trailers playing & $H 2 b$ & hold & Partial intermediary \\
\hline & Number of reports & $H 2 c$ & Not hold & no \\
\hline \multirow{2}{*}{ Online word-of-mouth } & Rating & $H 3 a$ & hold & Full intermediary \\
\hline & Number of reviews & $H 3 b$ & hold & no \\
\hline Purchase intention & Purchase intention & H4 & Partial hold & \\
\hline
\end{tabular}

\subsection{Strategies}

According to the above conclusions, there are significant correlations between product information, marketing information, online word-of-mouth and the willingness to buy that is significantly related to the purchasing behavior. And the purchase willingness serves as an intermediary role in the whole consumption decision-making process. In order to stimulate them to generate purchase intention and enhance consumer buying behavior. Therefore, we have the following suggestions:

1) Reasonablely control the length of the movie and select popular actors and directors

The length of a movie should be reasonably controlled. If the time is so short that consumers can't understand film' plot, or too long to appear the phenomenon of redundancies which consumers will feel narrative focus, then decrease the viewing effect. At the same time, filmmakers should choose the influencial and popular actors or directors to join in film production. In this way, consumers can make purchase behavior to increase box office revenues according to their experience and adoration of stars or directors.

2) Release the trailers and related videos in different stages

Different trailers can be released at different times, the closer you get to the release date, the more exciting it is. Likewise, you can also release some related video and shooting highlights, which is aimed at promoting the effectiveness of broadcasting film, and developing potential consumers' interest. By focusing on the number of trailers playing, the movie distributors prepare for the latter part of the film marketing campaign.

3) Initiate topics with consumers

Today's social media marketing more focuses on consumers interactive experience. Movie producers and distributors, actors can transmit their new film in businesses or privat online community, and start more film's topics or interact with fans and so on. Through this way, the consumers' purchase intention can be cultivated.

4) Encourage consumers to share online comments, ratings and so on

The number of online word-of-mouth has a greater impact on purchase intention, which confirms the conclusions of scholars such as Wenming Zuo. Therefore, under the social media marketing environment, we could encourage consumers to share their reviews on third-party word-of-mouth sites like "social networking + interests" and place high-quality reviews at top. However, simultaneously, we also should control the water army brushing comments and so on, and create a valuable, reliable and authentic online community for consumers.

\section{Conclusion and Limitations}

\subsection{Conclusion}

First of all, we established the theoretical model of Internet word-of-mouth, the marketing information and purchase intention and purchase behavior. Then from the Internet word-of-mouth, product information, marketing three aspects, we analyzed the relationships of various variables with purchase intention, and purchasing behavior, respectively. Furthermore, we verified whether purchase intention played the mediated role in the whole purchase decision process. At last, according to the analysis conclusions, we offered theoretical guidance and proposals on how to stimulate consumers' purchasing intention and generate purchase behavior.

Product information can significantly affect purchase intention. Among those variables in product information, the length of film had a greater impact on the purchase intention, which was conducive to control of the film playing time more reasonably and grasp the development of the plot better. In addition, in social media, marketing interactive information had a significant influence on purchase intention, the number of topics' influence on purchase intention was 
opposite bigger, which illustrated the topics number in the social media reflected consumer awareness of the product, the higher the number was, the more attention was. After surfing and looking through lots of topics information, which can stimulate the consumers' curiosity, and induce consumers to be interested in such topics, then generate purchase intention.

The number of online word-of-mouth had an important effect on purchase intention. The correlation analysis, regression analysis results fully verified that it can significantly affect the purchase intention, among which the online comments had the greatest influence on purchase intention. On one hand, this better explained people tended to consume such goods that the more people bought when making purchase decisions. On another hand, the more online comments were, the more comprehensive information of products were contained in it, which was more conducive to improve consumers' intuitive feelings and match their respective preferences.

Through the intermediary effect of purchase intention, online word of mouth, product information and marketing interactive information had influence on purchase behavior, respectively. That can be understood as, under the role of social media, between businesses and consumers constantly generated information releasing behaviors, namely the marketing information, product information, an sharing word-of- mouth, etc. By this way, that constantly stimulated consumer's purchase intention, and then brought out purchasing behavior, which reflected the intermediary role of the purchase intention.

\subsection{Limitations and Future Research}

Additionally, there are some shortages in this article:

(1) Sample data is limited. Due to the inaccessibility of internal data such as movie cost data, the lack of earlier media data, and real-time data etc., the total data is limited.

(2) We only talk about the number of marketing interactive information and online word-of-mouth, but don't discuss the text of the online word-of-mouth for usefulness and Sentiment analysis. This will be the next primary research direction.

Next paper, we will focus on the text of online word-of-mouth and topics, explore the consumer's concern attributes, and extract the consumers' interest by analyzing the sentiment score of each attribute.

\section{Acknowledgements}

This paper is supported by Beijing science and technology plan: research and development of key technologies for personalized consumption of Beijing animation derivatives (D171100003317001).

\section{References}

[1] M Li, \& C Wang. (2017). Explore the Influencing Factors of Socialized Media Characteristics on the Willingness to Pay. China Business and Market, 31 (8), 75-83.

[2] Jiao, F., \& Zhong, Y. (2015). What Factors Affect Purchase
Intention in Social Commerce: Based on Strong and Weak Relationship Theory. Management Review, 27(12), 99-109.

[3] Jin, Z. (2015). Research on the effects of micro-blog marketing on consumers' willingness to buy. China Business \& Market.

[4] Zhou, M. H., Li, P. M., \& Mou, Y. P. (2015). Effects of online reviews on purchase intention of consumers - the mediation of psychological distance. Soft Science, 29(1), 101-104.

[5] Liye, Z., Denghua, Y., \& Jingyi, Z. (2017). The Impact of Online User Reviews Quality and Commentators Rank on Consumer Purchasing Intention-The Moderating Role of Product Involvement. Management Review, 2009.

[6] Niu, G., Li, G., Geng, X., Zhou, Z., Tian, Y., \& Lian, S. (2016). The impact of online reviews' quality and quantity on online purchasing intention: the moderating effect of need for cognition. Journal of Psychological Science.

[7] Zheng, C., Han, Q., \& Wang, H. (2015). How do paid posters' comments affect your purchase intention. Nankai Business Review.

[8] Mullet, E. (1992). The probability + utility rule in attractiveness judgments of positive gambles $i$. Organizational Behavior \& Human Decision Processes, 52(2), 246-255.

[9] Ajzen, I., \& Fishbein, M. (1970). The prediction of behavior from attitudinal and normative variables. Journal of experimental Social Psychology, 6(4), 466-487.

[10] J Wei, \& Ying Zhang (2002). On the Perceived Mechanism of Advertising Information Drive. Journal of Zhejiang University (Humanities and Social Sciences), 32 (2), 126-130

[11] B Zhang, Z Huang, \& X Wen.(2014). Marketing Incentives, Psychological Reactions and Intentions and Behaviors of Purchase of Organic Vegetable Consumers - An Empirical Analysis Based on Ordered Logistic Regression Model. Journal of Agrotechnical (2), 47-56.

[12] J Bi. (2009). An Empirical Study on Internet Word of Mouth Affecting Consumer Purchase Intention. Journal of Intelligence, 28 (11), 46-51.

[13] W Zuo, X Wang, \& C Fan. (2014). Relationship between Electronic Word of Mouth and Purchase Intention in Social Commerce Environment: A Social Capital Perspective. Nankai Business Review, 17 (4), 140-150.

[14] X Du, J Ding, Z Xie, \& L Lei. (2016). An Empirical Study on the Impact of Online Reviews on Consumers' Purchasing Intention. Management Review, 28 (3), 173-183.

[15] S. Abraham Ravid, \& Basuroy, S. (2004). Managerial objectives, the $r$ - rating puzzle, and the production of violent films. Journal of Business, 7(S2), S155-S192.

[16] scott \& Sochay. (1994). Predicting the performance of motion pictures. Journal of Media Economics, 7(4), 1-20.

[17] Sonja Radas, \& Steven M. Shugan. (1998). Seasonal mar-keting and timing new product introductions. Journal of Marketing Research, 35(3), 296-315.

[18] Prag, J., \& Casavant, J. (1994). An empirical study of determinants of revenues and marketing expenditures in the motion picture industry. Journal of Cultural Economics, 18(3), 217-235. 
[19] Chang, Basuroy, S., Chatterjee, S., \& Ravid, S. A. (2003). How critical are critical reviews? the box office effects of film critics, star power, and budgets. Journal of Marketing, 67(4), 103-117.

[20] X Wu.(2008). Behind the bright stars - perspective of Chinese pop stars. Contemporary Cinema (5), 120-121.

[21] X Hu, Bo Li, \& Z Wu. (2013). The Analysis of the Factors Which Influence Film box office. Journal of Communication University of China (Natural Science Edition) Natural Science Edition, 20 (1), 62-67.

[22] K Guo. (2016). Research on Inter-Relationship among Online Review, Number of Screens and Box Office Revenue. Journal of Guangxi Normal University (Philosophy and Social Sciences Edition), 52 (6), 46-53.

[23] Y Hao, P Zou, Y Li, \& Q Ye. (2009). An Empirical Study on the Impact of Online Reviews Sentimental Orientation on Sale Based on Movie Panel Data. Management Review, 21 (10), 95-103.

[24] Z Liu. (2016). Online Evaluation, Film Heterogeneity and Box Office Revenue - Based on 177 Domestic Movies Data from 2014 to 2015 . Film Art (3), 68-72.

[25] Y Zhong. (2017) Research on Evaluation Model of Copyright Asset Based on Machine Learning. Shanghai Economic Research (6).
[26] Shugan, S., \& Swait, J. (2009). Enabling movie design and cumulative box office predictions using historical data and consumer intent-to-view. University of Florida.

[27] L Wang, \& J Jia. (2014). Forecasting box office performance based on online Search: Evidence from Chinese movie industry. Systems Engineering Theory and Practice, 34 (12), 3079-3090.

[28] C Sun, \& Y Liu. (2017). The Effects of Online Pre-launch Movie Trailers on the Box Office Revenue- Based on Text Sentiment Analysis Method. Chinese Journal of Management Science (10).

[29] S. Abraham Ravid, \& Basuroy, S. (2004). Managerial objectives, the $\mathrm{r}$ - rating puzzle, and the production of violent films. Journal of Business, 77(S2), S155-S192.

[30] Ridings, C. M., Gefen, D., \& Arinze, B. (2002). Some antecedents and effects of trust in virtual communities. Journal of Strategic Information Systems, 11(3-4), 271-295.

[31] Herr, P. M., Kardes, F. R., \& Kim, J. (1991). Effects of word-of-mouth and product-attribute information on persuasion: an accessibility-diagnosticity perspective. Journal of Consumer Research, 17(4), 454-462.

[32] Chatterjee, P. (2006). Online reviews: do consumers use them?. Advances in Consumer Research, 28. 